\title{
CENTRAL NERVOUS SYSTEM INTERNATIONAL PROGNOSTIC INDEX IMPACTS OVERALL SURVIVAL IN DIFFUSE LARGE B-CELL LYMPHOMA TREATED WITH R-CHOP IN A THIRD LEVEL CANCER CENTER FROM MEXICO: A SURVEY OF 642 PATIENTS
}

\author{
Rubén Solís-Armenta ${ }^{1}$, Bernardo Cacho-Díaz ${ }^{2}$, Olga Gutiérrez-Hernández ${ }^{3}$, \\ AND Myrna CANDELARIA-HeRNÁNDEZ ${ }^{3 *}$ \\ Departments of ${ }^{1}$ Hematology and ${ }^{2}$ Neuro-oncology, and ${ }^{3}$ Division of Clinical Research, Instituto Nacional \\ de Cancerología (INCan), Mexico City, Mexico
}

\begin{abstract}
Background: Central nervous system international prognosis index (CNS-IPI) is validated in European and the USA cancer databases. However, no validation has been done in Mexican population. Objective: The objective of the study was to assess the impact of the CNS-IPI on central nervous system (CNS) relapse and survival in Mexican patients with diffuse large B-cell lymphoma (DLBCL). Methods: In this retrospective analysis, clinical, biochemical, and histological variables and the CNS-IPI were analyzed. Results: Six hundred and forty-two patients with DBLCL were included in the study. The mean \pm SD age was $56.8 \pm 14.9$ years. Most had an ECOG of $0-1: 75 \%(n=484)$ had absence of B-symptoms and advanced disease (clinical stage: III-IV, $\mathrm{n}=433,67.4 \%$ ). According to the CNS-IPI, almost one-half were in the low-risk category. According to the CNS-IPI, CNS relapse rate was 1.36\% (95\% Cl: 83.2-92.8), 3.1\% (95\% Cl: 132.4-162.8), and 7.4\% (95\% Cl 61-91) for patients in the low-, intermediate-, and high-risk categories, respectively. The median overall survival in the high-risk group (CNS-IPI) was 22 months, and it has not been achieved after 80 months of follow-up for the other groups. Conclusions: CNS-IPI was associated with survival; therefore, we propose its use as a prognostic tool for prospective validation. (REV INVEST CLIN. 2021;73(4):231-7)
\end{abstract}

Key words: Diffuse large B-cell lymphoma. Central nervous system relapse. Prognosis. Survival. Central Nervous System International Prognosis Index.

*Corresponding author:

Myrna Candelaria-Hernández

E-mail: candelariahmgloria@gmail.com
Received for publication: 06-01-2021

Approved for publication: 17-02-2021

DOI: $10.24875 / R I C .21000010$

0034-8376 / (c) 2021 Revista de Investigación Clínica. Published by Permanyer. This is an open access article under the CC BY-NC-ND license (http://creativecommons.org/licenses/by-nc-nd/4.0/). 


\section{INTRODUCTION}

Diffuse large B-cell lymphoma (DLBCL) is the most common of all aggressive types of lymphomas ${ }^{1}$. Initially, the international prognostic index $(\mathrm{IPI})^{2}$ defined four prognostic groups of patients with response and survival. However, the advent of the rituximab era, mainly with the GELA ${ }^{3}, \mathrm{MINT}^{4}$, and RICOVER 60 studies $^{5}$, and other clinical scales, such as revised IPI $\left.\right|^{6,7}$, provided information for patients at risk of early relapse or progression. Recently, the metabolic findings on interim positron emission tomography (PET-CT) have also been incorporated to define prognostic groups ${ }^{8,9}$.

Rituximab is the standard of care in the treatment of B-cell lymphoproliferative malignancies. This antibody increases the long-term survival and modifies the natural history of the disease. Despite this improvement, the relapse at the central nervous system (CNS) in patients with DLBCL translates to an inferior prognosis since the average survival is of only $2-5$ months ${ }^{10,11}$. Different biomarkers that increase the risk of CNS infiltration have been identified, including the $M Y C$ rearrangement ${ }^{12}$, since patients with double or triple hit have CNS involvement, either at diagnosis or at relapse, in up to $50 \%$ of cases $^{13}$.

The CNS international prognosis index (CNS-IPI) was generated to identify patients with a higher risk of CNS relapse ${ }^{10}$ in patients enrolled in studies from the German High-grade non-Hodgkin Lymphoma Group, the MabThera International Trial, and validated in the British Columbia Cancer Agency Lymphoid Cancer database. However, this index has not been studied in a Hispanic-Mestizo population. Therefore, we conducted a study to evaluate the prognostic significance of the CNS-IPI on CNS relapse, and overall survival (OS), at the National Cancer Institute of Mexico.

\section{METHODS}

This retrospective analysis evaluated the impact of the CNS-IPI ${ }^{10}$, in addition to other clinical, biochemi$\mathrm{cal}$, and histological variables, on CNS relapse and OS of patients with diagnosed DLBCL. The inclusion criteria were as follows: patients $\geq 18$ years of age, with a histological diagnosis of DLBCL, treated with $\mathrm{R}-\mathrm{CHOP}$ at the National Cancer Institute (Instituto Nacional de Cancerología) in Mexico City, Mexico, from January 2011 through December 2018. The Ethics and Scientific Research Committees approved the review and analysis of clinical files (Rev/013/19).

Clinical characteristics included age, gender, comorbidities (diabetes mellitus, arterial blood hypertension, and cardiopathy), B symptoms, bulky disease, number of extranodal sites, clinical stage, bone marrow involvement, IPI score ${ }^{2}$, performance status defined by Eastern Cooperative Oncology Group (ECOG) scale $^{14}$, as well as the CNS-IPI ${ }^{10}$. The following biochemical parameters were also evaluated at diagnosis: lactic dehydrogenase (LDH), glucose, albumin, leukocytes, lymphocytes, hemoglobin, and beta $2 \mathrm{mi}-$ croglobulin levels. Diabetes mellitus was defined according to the American Diabetes Association crite$\mathrm{ria}^{15}$. The standard criteria from the European and the American College of Cardiology were used to define arterial blood hypertension ${ }^{16}$.

Immunohistochemistry (IHC) protocols were as follows. All tumor samples were fixed in $10 \%$ formalin for $10 \mathrm{~h}$ at room temperature and embedded in paraffin. Sections of $3 \mathrm{~mm}$ were prepared and mounted onto positively charged glass slides. Immunostaining was performed with an automated immunostainer (BenchMark ULTRA) using the following antibodies: CD20 (Dako, clone L26 1:400), CD3 (Dako, Polyclonal 1:200), CD10 (Cell Marque, clone 58C8 1:50), BCL2 (Cell Marque, clone 124 1:100), BCL6 (Cell Marque, clone G191E/AB 1:200), MUM1 (Dako, clone MUM1p 1:200), and MYC (Cell Marque, clone EP1321 1:150).

Histopathologic variables were GCB subtype versus non-GCB subtype, which was determined by the Hans nomogram ${ }^{17}$, as well as $B C L 2, B C L 6$, and MYC expression and double-hit lymphoma. Briefly, the GCB subtype was defined by the following expression patterns: CD10 ( \pm ), BCL6 (+), and MUM1 (-). Non-GCB subtype: CD10 (-), BCL6 ( \pm ), and MUM1 (+). The cutoff values for positivity were $50 \%$ for $\mathrm{BCL} 2$ expression, $30 \%$ for BCL 6 expression, and $40 \%$ for MYC expression, as has been described ${ }^{18}$. Lymphomas coexpressing MYC and BCL2 or BCL6 was considered double expressing, and fluorescence in situ hybridization (FISH) was performed to evaluate MYC rearrangements. When MYC rearrangements were present at least in $10 \%$, and $\mathrm{BCL} 2$ rearrangements were also documented, they were defined as a double-hit lymphoma. 
All patients were treated with 6 cycles of R-CHOP, as follows: rituximab $375 \mathrm{mg} / \mathrm{m}^{2}$, cyclophosphamide $750 \mathrm{mg} / \mathrm{m}^{2}$, doxorubicin $50 \mathrm{mg} / \mathrm{m}^{2}$, vincristine 1.4 $\mathrm{mg} / \mathrm{m}^{2}$ (total maximum dose $2 \mathrm{mg}$ ), and prednisone $100 \mathrm{mg} /$ day/5 days. The response was evaluated using PET-CT. In cases with increased glucose blood levels ( $>170 \mathrm{mg} / \mathrm{dL}$ ) that contraindicated the performance of PET/CT, only a computed tomography (CT) was done, and the response was evaluated by the Lugano 2014 criteria $^{19}$.

\section{Statistical analysis}

Descriptive analysis was done for demographic and clinical characteristics. Median and its interquartile range (IQR) were used as a measure of dispersion. The statistical differences between groups were calculated using the Chi-square test. To evaluate factors associated with response, CNS-relapse, and death, a logistic regression analysis was done with the following variables: age, gender, comorbidities, the presence of B symptoms, bulky disease, clinical stage, number of extranodal sites, bone marrow involvement, IPI score, performance status defined by ECOG scale, the CNS-IPI scale, as well as LDH, albumin, leukocytes, lymphocytes, and beta2 microglobulin levels, and histological variables (subtype, Ki 67, MYC expression, and double/triple hit) of DLBCL. The variables considered as statistically significant, were analyzed by multivariate analysis. Progression-free survival (PFS) was defined from the date of diagnosis until the date of failure to achieve a response, progression, or relapse. OS was defined as the period from diagnosis until the date of the last follow-up or death. Survival curves were calculated by the Kaplan-Meier method, and differences between subgroups were compared with the log-rank test. Cox regression analysis was used to identify the variables associated with CNS relapse, PFS, and OS. Hazard ratio, with $95 \%$ confidence interval $(95 \% \mathrm{Cl})$, was calculated for CNS relapse, according to the corresponding CNS-IPI groups. $p<0.05$ was considered statistically significant. Analyses were performed using SPSS, version 24.0 (IBM Corp., Armonk, NY, USA).

\section{RESULTS}

A total of 697 patients met the inclusion criteria; 55 were excluded because they were treated with chemotherapeutic regimens other than R-CHOP. Therefore, 642 cases were included in this study. The clinical characteristics are presented in table 1 . Median age was 57 years (IQR: 47-67 years). Most of the patients had a performance score according to the ECOG scale of $0-1(n=484,75 \%)$, with an absence of B-symptoms in $51 \%$, but with advanced disease, since the clinical stage was classified as IIIIV in 433 cases (67\%). According to CNS-IPI, 45.6\% $(n=293)$ were classified in the low-risk category (Table 2).

\section{Response}

The clinical response was considered complete in $71 \%(n=455)$, partial in $12 \%(n=78)$, and in $17 \%$ $(n=109)$, it progressed during chemotherapy. The following variables were associated with a worse response after the univariate analysis: ECOG $>2$; the presence of bulky disease; $>2$ extranodal sites involved; advanced disease (clinical Stage III + IV); IPI score categories defined as intermediate high or high, as well as intermediate or high groups defined by CNS-IPI. After multivariate analysis, only IPI status remained statistically significant for the response $(p=0.030)$.

\section{Follow-up}

The median follow-up was 44.18 (IQR: 17.6-68.7) months. During this period, 127 patients relapsed; most of them ( $n=111,87.4 \%$ ) relapsed outside the CNS, and only 16 had a CNS relapse. CNS relapse rate was $1.36 \%(4 / 293), 3.1 \%(10 / 322)$, and $7.4 \%$ $(2 / 27)$ for patients in the low-, intermediate-, and high-risk categories according to the CNS-IPI, respectively $(p=0.09)$.

\section{Survival}

Median PFS had not been achieved after 80 months of follow-up in the whole group (Fig. 1). When stratified by the CNS-IPI, the high-risk group had a median OS of 22 months, and it was not achieved during follow-up in the other groups $(p=0.0001)$. After Cox regression analysis, the only factor statistically significantly influencing PFS was the presence of bulky disease (R: 0.636 [95\% Cl: 0.431-0.937]), and the following factors were not statistically significant: ECOG, the presence of B symptoms or bulky disease, 
Table 1. Demographics and clinical characteristics of DLBCL patients

\begin{tabular}{|c|c|}
\hline Characteristic & $\begin{array}{c}\text { All patients } \\
\text { n (\%) }\end{array}$ \\
\hline Patients & $642(100)$ \\
\hline $\begin{array}{l}\text { Age years: median } \\
\text { (interquartile ranges) }\end{array}$ & $57(47-67)$ \\
\hline \multicolumn{2}{|l|}{ Gender } \\
\hline Female & $335(52.2)$ \\
\hline Male & $307(47.8)$ \\
\hline \multicolumn{2}{|l|}{ ECOG } \\
\hline $0-1$ & $484(75.4)$ \\
\hline $2-4$ & $158(24.6)$ \\
\hline Presence of B symptoms & $313(48.8)$ \\
\hline \multicolumn{2}{|l|}{ Serum $\beta 2$ microglobulin } \\
\hline Normal & $271(42.2)$ \\
\hline High & $262(40.8)$ \\
\hline Undetermined & $109(17.0)$ \\
\hline Presence of bulky disease & $300(46.7)$ \\
\hline \multicolumn{2}{|l|}{ Bone marrow aspirate* } \\
\hline Negative & $579(90.3)$ \\
\hline With infiltration & $42(6.5)$ \\
\hline Not performed & $21(3.2)$ \\
\hline \multicolumn{2}{|l|}{ Extranodal involvement } \\
\hline No & $273(42.5)$ \\
\hline Yes & $369(57.5)$ \\
\hline $1-2$ & $256(39.9)$ \\
\hline$>3$ & $113(17.6)$ \\
\hline \multicolumn{2}{|l|}{ Molecular type } \\
\hline Germinal center & $323(50.4)$ \\
\hline No germinal center & $212(33.0)$ \\
\hline Not performed & $92(14.3)$ \\
\hline Unclassifiable & $15(2.3)$ \\
\hline \multicolumn{2}{|l|}{ Clinical stage } \\
\hline 1 & $73(11.4)$ \\
\hline II & $136(21.2)$ \\
\hline III & $138(21.4)$ \\
\hline IV & $295(46)$ \\
\hline \multicolumn{2}{|l|}{ IPI } \\
\hline Low & $174(27.1)$ \\
\hline Low intermediate & $146(22.7)$ \\
\hline High intermediate & $158(24.6)$ \\
\hline High & $164(25.6)$ \\
\hline \multicolumn{2}{|l|}{ CNS risk involvement } \\
\hline Low & $293(45.6)$ \\
\hline Mild & $322(50.2)$ \\
\hline High & $27(4.2)$ \\
\hline
\end{tabular}

*Because of bone marrow involvement. SD: standard deviation; ECOG: Eastern Cooperative Oncology Group; IPI: International prognostic index; CNS: central nervous system. biochemical variables, molecular subtype, double-/ triple-hit DLBCL, clinical stage, IPI score, nor CNS-IPI.

The following factors were statistically significant for OS (determined by Cox regression analysis): risk groups by IPI score (HR: $0.328[95 \% \mathrm{Cl}=0.161-$ $0.666]) ; C N S-I P I(H R 0.311[95 \% \mathrm{Cl}=0.161-0.666])$ (Fig. $1 \mathrm{~b}$ and $1 \mathrm{C}$ ); and the presence of CNS relapse (HR: $0.32[95 \% \mathrm{Cl}=0.168-0.611]$ ) (Fig. 2a). Figure $2 \mathrm{~b}$ shows the risk of death, according to groups determined by the IPI-CNS index.

\section{DISCUSSION}

This study demonstrated that the CNS-IPI in MexicanMestizo population has a prognostic significance on CNS relapse and OS. Relapse at the CNS is a fatal complication in patients with DLBCL, with a median survival of only 2 months ${ }^{20,21}$. The CNS-IPI in patients with DLBCL is useful to discriminate groups at different risk of presenting CNS relapse ${ }^{10}$. Such patients have a very poor prognosis, and different clinical and biochemical parameters have been evaluated for these purposes. To date, only clinical variables have been demonstrated to impact on CNS progression.

Hollender et al. ${ }^{11}$ demonstrated that the parameters involved in compromise of the CNS were the presence of high levels of LDH, hypoalbuminemia, age $<60$ years, and infiltration of extranodal sites. After that, Schmitz et al. ${ }^{20}$ analyzed 2210 patients with aggressive B-cell lymphoma (including Burkitt and DLCGB), $2.6 \%$ of whom had CNS relapse, with the most significant risk factors being age (average 50 years), high levels of LDH, and clinical Stage III or IV. In accordance with both studies, we also demonstrated that high levels of LDH and clinical stage were associated with a higher risk of CNS relapse. In contrast to Schmitz results, the age was not significant for CNS relapse in our series.

Evaluation of cerebrospinal fluid (CSF) in patients with DLBCL in the absence of neurological symptoms is not routinely indicated ${ }^{21}$. However, the documentation of having a high risk in the CNS-IPI is an absolute indication for such procedure ${ }^{21-23}$. Cytology alone has $60 \%$ sensitivity for leptomeningeal infiltration and virtually no ability to detect parenchymal lymphoma. The addition of flow cytometry significantly increases 
Table 2. DLBCL patients, according to CNS prognostic index

\begin{tabular}{|c|c|c|c|c|}
\hline \multirow[t]{2}{*}{ Characteristics } & \multicolumn{3}{|c|}{ CNS prognostic index } & \multirow[t]{2}{*}{$\mathrm{p}$} \\
\hline & $\begin{array}{c}\text { Low risk, } \\
\text { n (\%) }\end{array}$ & $\begin{array}{c}\text { Intermediate, } \\
\text { n (\%) }\end{array}$ & $\begin{array}{l}\text { High risk, } \\
\text { n (\%) }\end{array}$ & \\
\hline Patients & $\begin{array}{c}293 \\
(45.6)\end{array}$ & $\begin{array}{c}322 \\
(50.2)\end{array}$ & $\begin{array}{c}27 \\
(4.2)\end{array}$ & - \\
\hline \multicolumn{5}{|l|}{ IPI } \\
\hline Low & $\begin{array}{c}154 \\
(52.5)\end{array}$ & $\begin{array}{l}20 \\
(6.2)\end{array}$ & - & 0.0001 \\
\hline Low-intermediate & $\begin{array}{c}101 \\
(34.4)\end{array}$ & $\begin{array}{c}43 \\
(13.3)\end{array}$ & $\begin{array}{c}2 \\
(7.4)\end{array}$ & \\
\hline Intermediate-high & $\begin{array}{c}30 \\
(10.2)\end{array}$ & $\begin{array}{c}119 \\
(36.9)\end{array}$ & $\begin{array}{c}9 \\
(33.3)\end{array}$ & \\
\hline High & $\begin{array}{c}8 \\
(2.7)\end{array}$ & & $\begin{array}{c}16 \\
(59.2)\end{array}$ & \\
\hline \multicolumn{5}{|l|}{ Clinical stage } \\
\hline$I+I I$ & $\begin{array}{c}174 \\
(59.3)\end{array}$ & $\begin{array}{c}33 \\
(10.2)\end{array}$ & $\begin{array}{c}2 \\
(7.4)\end{array}$ & 0.0001 \\
\hline$I I I+I V$ & $\begin{array}{c}119 \\
(40.7)\end{array}$ & $\begin{array}{c}289 \\
(89.8)\end{array}$ & $\begin{array}{c}25 \\
(92.6)\end{array}$ & \\
\hline \multicolumn{5}{|l|}{ Response } \\
\hline CR & $\begin{array}{c}229 \\
(78.1)\end{array}$ & $\begin{array}{c}212 \\
(65.8)\end{array}$ & $\begin{array}{c}14 \\
(51.8)\end{array}$ & \\
\hline PR & $\begin{array}{c}30 \\
(10.2)\end{array}$ & $\begin{array}{c}44 \\
(13.6)\end{array}$ & $414.8)$ & \\
\hline PD & $\begin{array}{c}34 \\
(11.6)\end{array}$ & $\begin{array}{c}66 \\
(20.4)\end{array}$ & $\begin{array}{c}9 \\
(33.3)\end{array}$ & 0.020 \\
\hline Relapsed & $\begin{array}{c}55 \\
(18.7)\end{array}$ & $\begin{array}{c}67 \\
(20.8)\end{array}$ & $\begin{array}{c}5 \\
(18.5)\end{array}$ & 0.2 \\
\hline CNS relapse $95 \% \mathrm{Cl}$ & $\begin{array}{c}4 \\
(1.36)\end{array}$ & $\begin{array}{c}10 \\
(3.1)\end{array}$ & $\begin{array}{c}2 \\
(7.4)\end{array}$ & 0.01 \\
\hline \multirow[t]{2}{*}{ Mean PFS 95\% Cl } & 88.04 & 147.3 & 76.35 & 0.281 \\
\hline & $83.2-92.9$ & $132-162.3$ & $61-91.6$ & \\
\hline Mean OS 95\% Cl & $\begin{array}{c}130.45 \\
(123-137)\end{array}$ & $\begin{array}{c}134.1 \\
(123-137)\end{array}$ & $\begin{array}{c}58.24 \\
(140-156)\end{array}$ & 0.0001 \\
\hline
\end{tabular}

IPI: International Prognostic Index; CR: complete response; PR: partial response; PD: progressive disease; CNS: central nervous system; PFS: progression-free survival (months); OS: overall survival (months); Cl: confidence interval.

sensitivity in the diagnosis of CNS involvement, which can be found in approximately $10 \%$ of high-risk patients ${ }^{21}$.

The differences in the biological behavior of DLBCL remain an objective of research. Double-hit DLBCL has a higher frequency of early extranodal relapse, including at $\mathrm{CNS}^{24}$. In the same direction, the series by Savage et al. showed that CNS relapse was more significant in the group of patients with double expression (2-year risk of CNS relapse in double expressors vs. non-double expressors, $9.7 \%$ vs. $2.2 \%$; $p=0.01$ ), surpassing double-hit lymphomas ${ }^{25}$.

Klanova et al. ${ }^{26}$ evaluated in 1418 patients with DLB$\mathrm{CL}$ the impact of the CNS- IPI scale, the cell of origin (COO), and MYC/BCL2 (double expressor) on CNS relapse. These authors concluded that achieving a CNS-IPI higher than 4, as well as the COO' ( $A B C$ ), had a statistical significance on CNS relapse risk, unlike cases with MYC/BCL2 expression, which were not significant in this series. In contrast to these authors, in 
Figure 1. Overall survival in the whole group (A), and stratified by IPI score (B) and CNS-prognostic index (C).
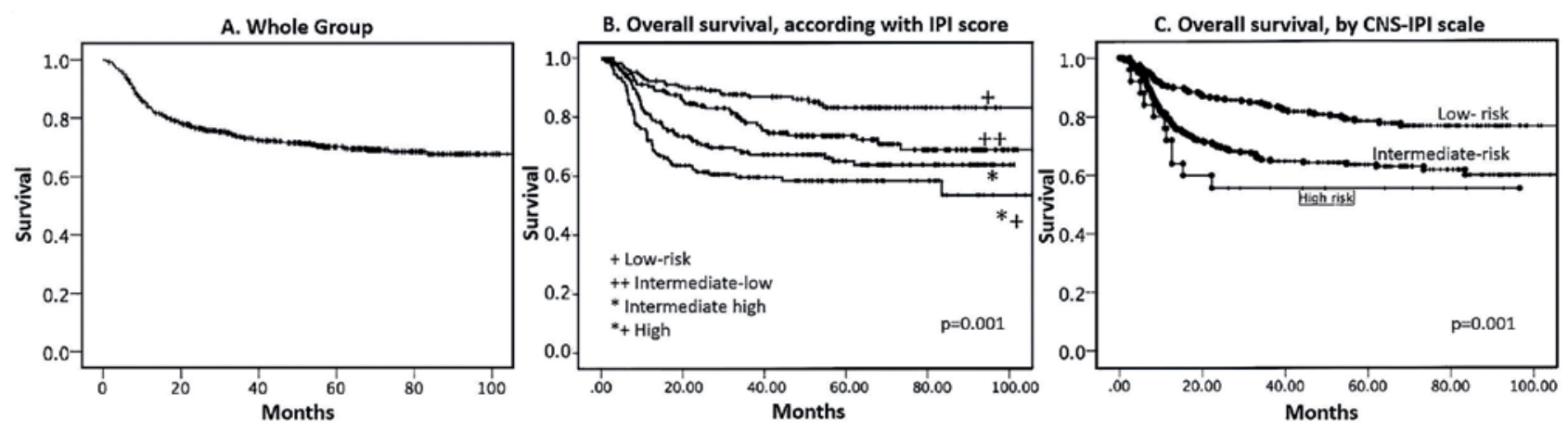

Figure 2. Impact of CNS relapse on overall survival (OS). (A) OS by CNS relapse status. (B) Risk of death, according to CNS-IPI.
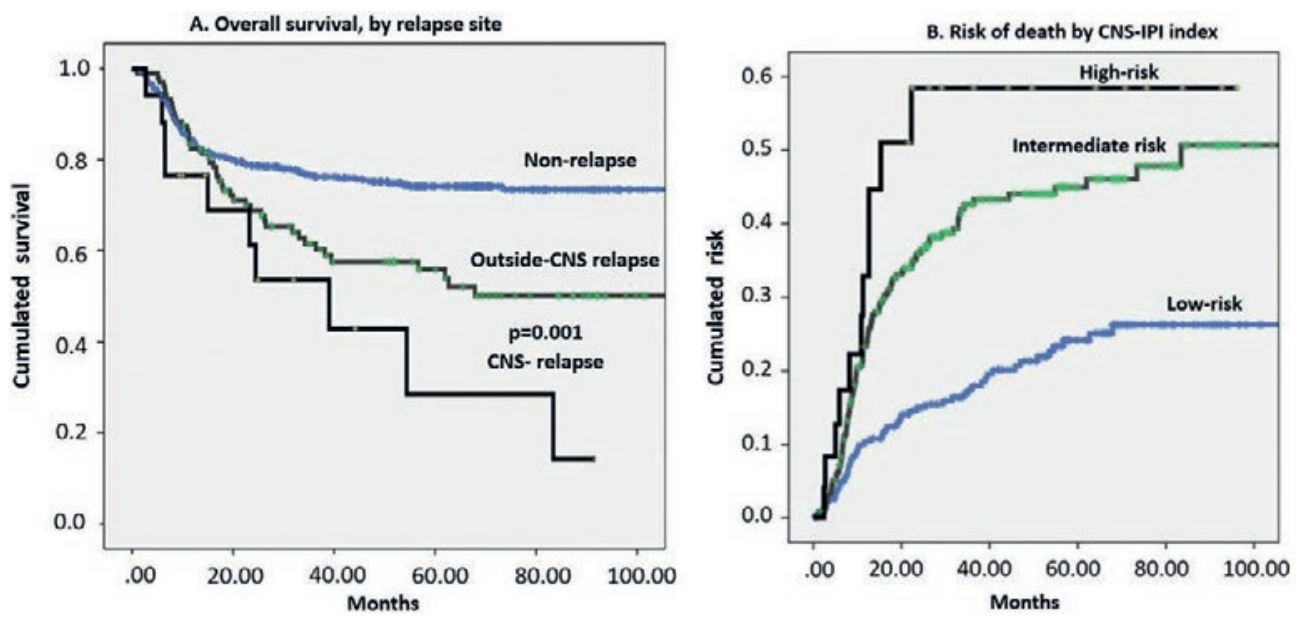

our study, the COO was not significant to consider a risk of CNS relapse, and neither was the presence of double-hit lymphomas.

Different series have demonstrated the usefulness of the CNS-IPI in determining the impact of CNS relapse prediction, with a follow-up of 2 years ${ }^{10,24,25}$. Our series agreed with these authors. As shown in figure $1 c$, we demonstrated an impact in OS since the follow-up was longer than in previous studies. In agreement with other authors ${ }^{10,11,26}$, the benefit of CNS prophylaxis in prognosis and survival in high-risk patients according to the CNS-IPI is justified. Different strategies have been proposed, including intrathecal (IT) chemotherapy and high-dose methotrexate. IT chemotherapy does not penetrate the brain parenchyma and may be insufficient to avoid CNS relapses. Systemic high-dose methotrexate penetrates to leptomeningeal and parenchymal compartments, but its toxicity may limit this approach in older patients ${ }^{27}$. Therefore, considering the impact on OS, the addition of high-dose methotrexate in these high-risk patients should be considered.

The limitations of this study include that it is retrospective and single center. However, the population studied is large, even when compared to other international series.

This study showed that the CNS-IPI is associated with survival and not only with CNS relapse. Therefore, we propose its use as a prognostic tool for a prospective validation.

\section{REFERENCES}

1. Horwitz SM, Zelenetz AD, Gordon LI, Wierda WG, Abramson JS, Advani RH, et al. NCCN guidelines insights: non-Hodgkin's lym- 
phomas, Version 3.2016. J Natl Compr Canc Netw. 2016; 14: 1067-79.

2. The International Non-Hodgkin's Lymphoma Prognostic Project. A predictive model for aggressive non-Hodgkin's lymphoma. $\mathrm{N}$ Engl J Med. 1993;329:987-94.

3. Coiffier B, Thieblemont C, Van Den Neste E, Lepeu G, Plantier I, Castaigne $\mathrm{S}$, et al. Long-term outcome of patients in the $\mathrm{LNH}$ 98.5 trial, the first randomized study comparing rituximabCHOP to standard CHOP chemotherapy in DLBCL patients: a study by the Groupe d'Etudes des Lymphomes de l'Adulte. Blood. 2010;116:2040-5.

4. Pfreundschuh M, Kuhnt E, Trümper L, Osterborg A, Trneny M, Shepherd L, et al. CHOP-like chemotherapy with or without rituximab in young patients with good-prognosis diffuse largeB-cell lymphoma: 6-year results of an open-label randomised study of the MabThera International Trial (MInT) Group. Lancet Oncol. 2011;12:1013-22.

5. Pfreundschuh M, Schubert J, Ziepert M, Schmits R, Mohen M Lengfelder $\mathrm{E}$, et al. Six versus eight cycles of bi-weekly CHOP-14 with or without rituximab in elderly patients with aggressive CD20+ B-cell lymphomas: a randomised controlled trial (RICOVER-60). Lancet Oncol. 2008;9:105-16.

6. Sehn LH, Berry B, Chhanabhai M, Fitzgerald C, Gill K, Hoskins P, et al. The revised international prognostic index (R-IPI) is a better predictor of outcome than the standard IPI for patients with diffuse large B-cell lymphoma treated with R-CHOP. Blood. 2007;109:1857-61.

7. Zhou Z, Sehn LH, Rademaker AW, Gordon LI, Lacasce AS, Crosby-Thompson A, et al. An enhanced International Prognostic Index (NCCN-IPI) for patients with diffuse large B-cell lymphoma treated in the rituximab era. Blood. 2014;123:837-42.

8. Kitajima K, Okada M, Yoshihara K, Tokugawa T, Sawada A, Yoshihara S, et al. Predictive value of interim FDG-PET/CT findings in patients with diffuse large B-cell lymphoma treated with RCHOP. Oncotarget. 2019;10:5403-11.

9. Oñate-Ocaña LF, Cortes V, Castillo-Llanos R, Terrazas A, GarciaPerez O, Pitalua-Cortés Q, et al. Metabolic tumor volume changes assessed by interval 18 fluorodeoxyglucose positron emission tomography-computed tomography for the prediction of complete response and survival in patients with diffuse large B-cell lymphoma. Oncol Lett. 2018;16:1411-8.

10. Schmitz N, Zeynalova S, Nickelsen M, Kansara R, Villa D Sehn $\mathrm{LH}$, et al. CNS international prognostic index: a risk model for CNS relapse in patients with diffuse large B-Cell lymphoma treated with R-CHOP. J Clin Oncol. 2016;34:3150-6.

11. Hollender A, Kvaloy S, Nome O, Skovlund E, Lote K, Holte H. Central nervous system involvement following diagnosis of non-Hodgkin's lymphoma: a risk model. Ann Oncol. 2002;13:1099-107.

12. Savage KJ, Johnson NA, Ben-Neriah S, Connors JM, Sehn LH, Farinja $\mathrm{P}$, et al. MYC gene rearrangements are associated with a poor prognosis in diffuse large B-cell lymphoma patients treated with R-CHOP chemotherapy. Blood. 2009;114:3533-7.

13. Oki $Y$, Noorani M, Lin P, Davis RE, Neelapu SS, Ma L, et al. Double hit lymphoma: the MD Anderson Cancer Center clinical experience. Br J Haematol. 2014;166:891-901.
14. Oken MM, Creech RH, Tormey DC, Horton J, Davis TE, McFadden ET, et al. Toxicity and response criteria of the Eastern Cooperative Oncology Group. Am J Clin Oncol. 1982;5:649-55.

15. American Diabetes Association. 2. Classification and diagnosis of diabetes: standards of medical care in diabetes-2020. Diabetes Care. 2020;43:S14-31.

16. Whelton P, Williams B. The 2018 European Society of Cardiology/European Society of Hypertension and 2017 American College of Cardiology/American Heart Association Blood Pressure Guidelines: more similar than different. JAMA. 2018;320: 1749-50.

17. Hans CP, Weisenburger DD, Greiner TC, Gascoyne RD, Delabie J, Ott $G$, et al. Confirmation of the molecular classification of diffuse large B-cell lymphoma by immunohistochemistry using a tissue microarray. Blood. 2004;103:275-82.

18. Swedlow SH, Campo E, Pileri SA, Harris NL, Stein H, Sibert R, et al. The 2016 revision of the World Health Organization classification of Iymphoid neoplasms. Blood. 2016;127:2375-90.

19. Cheson BD, Fisher R, Barrington SF, Cavalli F, Schwartz LH, Zucca $E$, et al. Recommendations for initial evaluation, staging, and response assessment of Hodgkin and non-Hodgkin lymphoma: the Lugano classification. J Clin Oncol. 2014;32:3059-68.

20. Schmitz N, Zeynalova S, Glass B, Kaiser U, Cavallin-Stahl E, Wolf $\mathrm{M}$, et al. CNS disease in younger patients with aggressive B-cell lymphoma: an analysis of patients treated on the Mabthera International Trial and trials of the German High-Grade Non-Hodgkin Lymphoma Study Group. Ann Oncol. 2012;23: 1267-73.

21. Savage KJ. Secondary CNS relapse in diffuse large B-cell lymphoma: defining high-risk patients and optimization of prophylaxis strategies. Hematol Am Soc Hematol Educ Program. 2017;2017:578-86

22. Qualls D, Abramson JS. Advances in risk assessment and prophylaxis for central nervous system relapse in diffuse large Bcell lymphoma. Haematologica. 2019;104:25-34.

23. National Comprehensive Cancer Network. Diffuse Large B-Cell Lymphoma (version 1.2020). United States. Retrieved from https://www.nccn.org/professionals/physician_gls/pdf/b-cell. pdf (reviewed on January 26th, 2021)

24. Li S, Lin P, Fayad LE, Lennon PA, Miranda RN, Yin CC, et al. B-cell lymphomas with MYC/8q24 rearrangements and IGH@ $\mathrm{BCL} 2 / \mathrm{t}(14 ; 18)(\mathrm{q} 32 ; \mathrm{q} 21)$ : an aggressive disease with heterogeneous histology, germinal center B-cell immunophenotype and poor outcome. Mod Pathol. 2012;25:145-56.

25. Savage K, Slack G, Mottock A, Sehn LH, Villa D, Kansara R, et al. Impact of dual expression of MYC and BCL2 by immunohistochemistry on the risk of CNS relapse in DLBCL. Blood. 2016; 127:2182-8

26. Klanova M, Sehn LH, Bence-Bruckler I, Cavallo $F$ Jin J, Martelli $M$, et al. Integration of cell of origin into the clinical CNS International Prognostic Index improves CNS relapse prediction in DLBCL. Blood. 2019;133:919-26.

27. Kansara R. Central nervous system prophylaxis strategies in diffuse large B cell lymphoma. Curr Treat Options Oncol. 2018;19:52. 